\title{
Joint remodeling outcome of serum levels of Dickkopf-1 (DKK1), cartilage oligomeric matrix protein (COMP), and C-telopeptide of type II collagen (CTXII) in rheumatoid arthritis
}

\author{
NAGLAA K. IDRISS ${ }^{l}$, RANIA M. GAMAL', MARWA A. GABER I, EMAN H. EL-HAKEIM ${ }^{2}$, \\ NEVIN HAMMAM², ABEER M. GHANDOUR ${ }^{2}$, MARWA MAHMOUD ABDELAZIZ2, SAMAR H. GOMA ${ }^{2}$
}

${ }^{1}$ Department of Medical Biochemistry, Assiut University, Assiut, Egypt

${ }^{2}$ Department of Rheumatology, Rehabilitation and Physical Medicine, Assiut University Hospital, Assiut, Egypt

\begin{abstract}
Introduction: Rheumatoid arthritis $(R A)$ is the most widespread chronic inflammatory rheumatic disease over the world. It is characterized by chronic proliferation of synovium, cartilage destruction, and periarticular erosion/bone loss. We investigated the serum levels of the C-telopeptide of type II collagen (CTX-II), Dickkopf-1 (DKK1), and cartilage oligomeric matrix protein (COMP) in relationship to the disease activity.

Material and methods: Serum COMP, CTX-II, and DKK1 levels were measured in 63 RA patients and 50 person age and gender matched as a healthy controls by ELISA test. Disease activity score (DAS) were calculated.

Results: The mean level of and COMP and CTX-II were significantly higher in patients with RA than in healthy controls $(5.71 \pm 7.04 \mathrm{vs} .2 .70 \pm 1.31 \mathrm{ng} / \mathrm{ml}$, and $0.45 \pm 0.27 \mathrm{vs} .0 .23 \pm 0.16 \mathrm{ng} / \mathrm{ml}$, respectively; $p<0.001)$. Also, DKK1 serum levels were significantly higher in patients with RA than in healthy controls $(6970.68 \pm 7566.68 \mathrm{vs} .3276 .96 \pm 1306.77 \mathrm{pg} / \mathrm{m} ; \mathrm{p}<0.001)$. There was a positive significant correlation between DKK1 and swollen joint $(r=0.42, p<0.001)$. There were no significant differences in the number of patients, gender, the duration of RA disease, DAS, and RF. Sensitivity was $58.7 \%$ and specificity was $85.7 \%$ at a cut-off point (> $3.6 \mathrm{ng} / \mathrm{ml})$ for serum COMP in RA patients, while, sensitivity was $100 \%$ and specificity was $52.4 \%$ at a cut-off point $(>0.15 \mathrm{ng} / \mathrm{ml})$ for serum CTX-II and sensitivity was $68.3 \%$ and specificity was $95.2 \%$ at a cut-off point (> $4876 \mathrm{pg} / \mathrm{ml}$ ) for serum DKK1.

Conclusions: Measurement of some serological biomarkers such as CTX-II, COMP, and DKKI that reflect bone and cartilage destruction in RA patients could be used to indicate disease activity and early joint affection.
\end{abstract}

Key words: rheumatoid arthritis (RA), C-telopeptide of type II collagen (CTX-II), Dickkopf-1 (DKK1), cartilage oligomeric matrix protein (COMP), disease activity.

(Centr Eur J Immunol 2020; 45 (1): 73-79)

\section{Introduction}

Rheumatoid arthritis (RA) is characterized by chronic proliferation of synovium, cartilage destruction, and periarticular erosion/bone loss [1]. This strong interface between subchondral bone, cartilage, and synovial membrane of the inflamed joint induce a release of particular protein fragments into the serum and urine, which may be used as specific biomarkers [2]. The articular ligament predominantly comprises of two essential lattice proteins sort II collagen and proteoglycans including aggrecan. Sort II collagen is framed by the relationship of three indistin- guishable $\alpha 1$ chains, in a triple helix aside from the two finishes, in the $\mathrm{C}$ - and $\mathrm{N}$-telopeptides. They are integrated by synovial cells and chondrocytes because of the impact of development of components and cytokines [3-5] with the arrangement of neoepitopes, which are discharged into the dissemination and discharged in urine. In scientific investigations, a relationship between urinary sort II collagen C-telopeptide (u) CTX-II and radiographic hip joint space narrowing and hip torment was discovered $[6,7]$.

Cartilage oligomeric matrix protein (COMP) is a $435-\mathrm{kDa}$ homopentameric non-collagenous extracellular matrix pro-

Correspondence: Eman H. El-Hakeim, PhD, Department of Rheumatology, Rehabilitation and Physical Medicine, Assiut University Hospital, 71526 Assuit, Egypt, e-mail: emanelhakeim@aun.edu.eg Submitted: 20.12.2017; Accepted: 1.03.2018 
tein of the thrombospondin family with calcium binding proteins [8]. COPM is essentially situated in the hyaline ligament on a very basic level to hold on the integrity of collagen arrange; it is additionally present in ligaments, skin, and synovial fibroblasts $[9,10]$. COMP has been broadly considered in RA, with a few reviews presuming that COMP can possibly be an analytic and prognostic pointer, a marker of ailment seriousness, and a marker of the impact of treatment [11-17]. Though, different analysts indicated contradicting sees for the utilization of COMP as a natural marker for RA [18-20]. This shows the need for a more noteworthy comprehension of the biochemical ramifications of COMP in RA finding, forecast, and treatment observing.

While most conditions of arthritis include joint remodeling, a unique feature of RA is the existence of bone erosion only without signs of repair (osteophytes). It has been suggested that suppression of signaling in the Wingless (Wnt) signaling pathway is the key master in the imbalance between bone resorption and replacement signals in RA joints [21]. Activation of the "canonical Wnt signaling pathway" (involving Wnt and $\beta$-catenin) upregulates osteoprotegerin (OPG), which blocks RANKL-induced osteoclastogenesis and results in the inhibition of bone resorption [22-24].

Dickkopf-1 (DKK1), an endogenous inhibitory factor in the canonical Wnt signaling, could augment the expression of the osteoclast differentiation factors and RANKL together with the decrease in the expression of OPG. In addition, a results of a study have shown a vital part of DKK1 in the advancement of synovial angiogenesis [23]. Moreover, other researches have demonstrated that upregulation of DKK1 may actuate tumor corruption figure receptor-1 tumor necrosis factor (TNF receptor-1) in developing particular mesenchymal cells $[25,26]$, and TNF- $\alpha$ inhibitor could downregulate DKK1 in ankylosing spondylitis [27].

The objective of this study was to evaluate differences in serum levels of CTX-II, COMP, and DKK1 in patients with RA compared to healthy controls, and to investigate the correlation between these markers and disease activity.

\section{Material and methods}

Sixty-three patients fulfilling the 2010 ACR-EULAR classification criteria for RA [28] were recruited from the in-patients and out-patients' clinic of the Rheumatology, Rehabilitation, and Physical Medicine Department of Assiut University hospitals. Full history recording with thorough general and musculoskeletal examination (age, sex, disease duration, age of onset, duration of morning stiffness, presence of extra-articular manifestations, and their current treatment) were completed.

The disease activity in RA patients was assessed by the 28 joint count disease activity score (DAS28), using the number of swollen and tender joints, erythrocyte sedimentation rate (ESR), and patient's global status and pain evaluated by the visual analogue scale (VAS), ranging from 0 to $100 \mathrm{~mm}$ [29].

Fifty persons age and sex matched apparently healthy individuals from the hospital personnel; undergraduates, medical, and nursing staffs were also included as a control group. The local ethics committee approved the study and all participants gave a written informed consent before being enrolled into the study.

\section{Serum samples and laboratory measures}

Five milliliters of peripheral blood were collected after an overnight fasting from each patient and control participant in two EDTA tubes. One set of the tubes were used for complete blood count (CBC), first-hour erythrocyte sedimentation rate (ESR) by Westergren's method in $\mathrm{mm} / \mathrm{hour}$, and rheumatoid factor (RF) tests in the same day of blood collection. The other samples were allowed to clot and centrifuged at 3,000 rpm for $20 \mathrm{~min}$, after which, a serum were collected, aliquoted, and kept frozen at $-20^{\circ} \mathrm{C}$ until analysis in the biochemistry lab. Assays were carried out to determine serum levels of CTX-II, COMP, DKK1,TNF- $\alpha$, and interleukin 17 (IL-17) by a sandwich enzyme-linked immunosorbent assay (ELISA).

Assays were carried out to determine serum levels of COMP, CTX-II, DKK1,TNF- $\alpha$, and interleukin 17 (IL-17) utilizing monoclonal antibodies directed against separate antigens of human serum COMP, CTX-II, and DKK1. The kits for COMP and CTX-II assay were provided by Elabscience Biotechnology Co., while DKK1 was provided by Thermo-Fisher Scientific. These sandwich ELISAs were carried out according to the supplier's protocols, and optical densities were determined using an automated reader (BioRad Co., USA).

\section{Statistical analysis of data}

The clinical and laboratory data were collected, categorized, and processed by Statistical Package for Social Sciences (SPSS), version 20. Continuous data were expressed as mean \pm standard deviation (SD), while the categorical data were expressed as numbers and percentages. For statistical evaluation, unpaired Student's $t$-test was used for comparison of continuous variables between the two groups. Mann-Whitney $U$ test was used to compare non-parametric variables. Categorical data were analyzed by the $\chi^{2}$ test. Spearman rank correlation coefficient was used to evaluate the correlation between different parameters in each group and also with studied risk factors. Multivariate logistic regression analysis of variables was additionally used. A probability ( $p$-value) of $<0.05$ was considered statistically significant.

The threshold value for optimal sensitivity and specificity of our markers were determined by the receiver operating characteristics (ROC) curve, which was plotted by calculating sensitivity and specificity at several cut-off points. The ROC curve can be used to select the best cut-off for identify- 
ing the sensitivity and specificity of the diagnostic test. The area under the curve (AUC) of the ROC plots ranged from 1.0 (perfect separation of test values into two groups) to 0.5 (no distributional differences). An AUC $>0.7$ indicated a discriminating strength of statistical significance and AUC $>0.8$ indicated excellent discriminating power of the test [30].

\section{Results}

Sixty-three patients were enrolled into this study, with 57 females and 6 males. Healthy control $(n=50)$ consisted

Table 1. Demographic data for both rheumatoid arthritis (RA) patients and controls, and clinical data for RA patients

\begin{tabular}{|c|c|c|c|c|c|}
\hline \multirow[t]{2}{*}{ Parameter } & \multicolumn{2}{|c|}{$\begin{array}{l}\text { RA patients } \\
\quad(n=63)\end{array}$} & \multicolumn{2}{|c|}{$\begin{array}{c}\text { Controls } \\
(n=50)\end{array}$} & \multirow[t]{2}{*}{$p$-value } \\
\hline & $n$ & $\%$ & $n$ & $\%$ & \\
\hline Age, years & \multicolumn{2}{|c|}{$45.89 \pm 11.39$} & \multicolumn{2}{|c|}{$44.92 \pm 9.65$} & 0.632 \\
\hline \multicolumn{6}{|l|}{ Gender } \\
\hline Male & 6 & 9.5 & 12 & 24.0 & 0.170 \\
\hline Female & 57 & 90.5 & 38 & 76.0 & \\
\hline Disease duration, years & \multicolumn{2}{|c|}{$8.3 \pm 6.05$} & & & \\
\hline Morning stiffness, hours & \multicolumn{2}{|c|}{$0.36 \pm 0.55$} & & & \\
\hline Number of swollen joints & \multicolumn{2}{|c|}{$2.49 \pm 2.55$} & & & \\
\hline Number of tender joints & \multicolumn{2}{|c|}{$6.69 \pm 5.81$} & & & \\
\hline Patient global score & \multicolumn{2}{|c|}{$16.69 \pm 16.15$} & & & \\
\hline DAS28 & \multicolumn{2}{|c|}{$4.41 \pm 1.17$} & & & \\
\hline \multicolumn{6}{|l|}{ Grads of DAS28 } \\
\hline Remission & 4 & 6.3 & & & \\
\hline Low & 6 & 9.5 & & & \\
\hline Moderate & 35 & 55.6 & & & \\
\hline High & 18 & 28.6 & & & \\
\hline \multicolumn{6}{|l|}{ Rheumatoid factor } \\
\hline Positive & 57 & 90.5 & & & \\
\hline Negative & 6 & 9.5 & & & \\
\hline \multicolumn{6}{|l|}{ Medications (dose range) } \\
\hline \multicolumn{6}{|l|}{ DMARDs } \\
\hline MTX (12.5-20 mg) & 47 & 74.6 & & & \\
\hline Leflunomide (20 mg) & 30 & 47.6 & & & \\
\hline HCQ (200-400 mg) & 53 & 84.1 & & & \\
\hline SSZ (500-2000 mg) & 8 & 12.6 & & & \\
\hline NSAIDs & 24 & 38 & & & \\
\hline $\begin{array}{l}\text { Steroids prednisolone } \\
(2.5-15 \mathrm{mg})\end{array}$ & 19 & 30.1 & & & \\
\hline
\end{tabular}

of 38 females and 12 males $(p=0.170)$, with a mean age of $45.89 \pm 11.39$ years and $44.92 \pm 9.65$ years, respectively $(p=0.632)$. All the patients were diagnosed with rheumatoid arthritis, and the mean duration of disease was $8.3 \pm 6.05$ in years, morning stiffness was $0.36 \pm 0.55$ in hours,

Table 2. Comparison between rheumatoid arthritis (RA) patients and controls regarding markers

\begin{tabular}{lccc}
\hline Parameter & $\begin{array}{c}\text { RA patients } \\
(\boldsymbol{n}=\mathbf{6 3})\end{array}$ & $\begin{array}{c}\text { Controls } \\
(\boldsymbol{n}=\mathbf{5 0})\end{array}$ & $\boldsymbol{p}$-value \\
\hline $\mathrm{COMP} \mathrm{ng} / \mathrm{ml}$ & $5.71 \pm 7.04$ & $2.70 \pm 1.31$ & $<0.001^{* *}$ \\
\hline $\mathrm{CTX}-\mathrm{II} \mathrm{ng} / \mathrm{ml}$ & $0.45 \pm 0.27$ & $0.23 \pm 0.16$ & $<0.001^{* *}$ \\
\hline $\mathrm{DKK} 1 \mathrm{pg} / \mathrm{ml}$ & $5619.1 \pm 1731.4$ & 3276.96 & $<0.001^{* *}$ \\
& & \pm 1306.77 & \\
\hline $\mathrm{TNF}-\alpha \mathrm{pg} / \mathrm{ml}$ & $6.4 \pm 2.25$ & $1.55 \pm 0.61$ & $<0.001^{* *}$ \\
\hline $\mathrm{IL}-17 \mathrm{pg} / \mathrm{ml}$ & $14.3 \pm 3.88$ & $5.86 \pm 1.09$ & $<0.001^{* *}$ \\
\hline $\begin{array}{l}\text { TNF- } \alpha-\text { tumor necrosis factor } \alpha, \text { IL-17 - interleukin 17, } \\
\text { significant difference }(p<0.05),{ }^{* *} \text { statisticallically significant difference }(p<0.01)\end{array}$
\end{tabular}

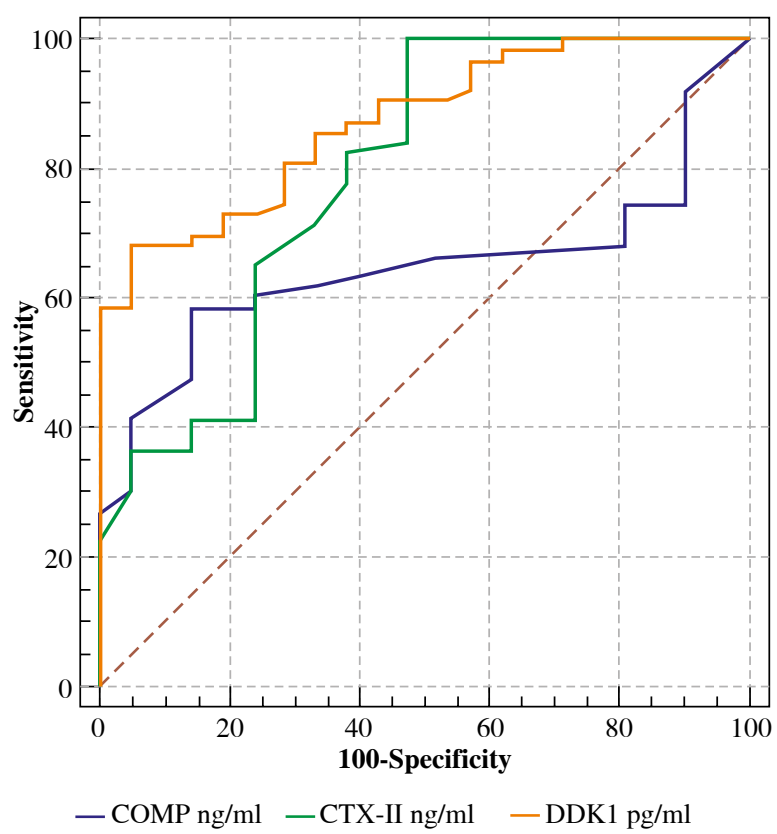

COMP ng/ml AUC: 0.65

Cut-off: $>3.6$

Sensitivity: $58.7 \%$

Specificity: $85.7 \%$

PPV: $92.5 \%$

NPV: $40.9 \%$

Accuracy: $72.2 \%$

$A U C$ - area under

Fig. 1. ROC curve of COMP, CTX-II, and DKK1 between RA patients and control group 
and the mean of DAS28 score was $4.41 \pm 1.17$. Fifty-seven patients were rheumatoid factor (RF) positive (90.5\%). All this data are presented in Table 1.

Table 2 shows the comparison between RA patients and control regarding markers. The mean levels of serum COMP in ng/ml, CTX-II in ng/ml, DKK1 in $\mathrm{pg} / \mathrm{ml}$, TNF- $\alpha \mathrm{pg} / \mathrm{ml}$, and IL-17 pg/ml were $5.71 \pm 7.04,0.45$ $\pm 0.27,5619.1 \pm 1731.4: 2.70 \pm 1.31,0.23 \pm 0.16,3276.96$ $\pm 1306.77,6.4 \pm 2.25: 1.55 \pm 0.61$, and $14.3 \pm 3.88: 5.86$ \pm 1.09 , respectively, with highly significant difference ( $p=0.001$, for five biomarkers).

COMP showed sensitivity of $58.7 \%$ and specificity of $85.7 \%$, with cut-off value $>3.6 \mathrm{ng} / \mathrm{ml}$, CTX-II demonstrated sensitivity of $100 \%$ and specificity of $52.4 \%$, with cut-off value $>0.15 \mathrm{ng} / \mathrm{ml}$, and also DKK1 showed sensitivity of $68.3 \%$ and specificity of $95.2 \%$, with cut-off value $4876 \mathrm{pg} / \mathrm{ml}$ (Fig. 1).

Table 3 shows a correlation of serum levels of COMP, CTX-II, and DKK1 with the age, disease duration, morning stiffness, number of swollen joint, number of tender joint, patient global assessment, DAS28, WBCs, ESR, HB, platelet count, TNF- $\alpha$, and IL-17. COMP were significantly correlated with number of swollen joint, No of tender joint, patient global assessment, DAS28, ESR, HB, TNF- $\alpha$, and IL-17 $(r=-0.28, p<0.026 ; r=-0.33, p<0.007 ; r=-0.4$, $p<0.001 ; r=-0.52, p<0.001 ; r=-0.39, p<0.002$; $r=0.25, p<0.04 ; r=-485, p=0.000$; and $r=-0.425$, $p=0.001)$, respectively. CTX-II was significantly correlated only with patient age $(r=0.28, p<0.026)$. DKK1 serum levels were significantly correlated with number of swollen joint, number of tender joint, patient global assessment, DAS28, ESR, HB, and platelet count $(r=0.5, p<0.001$; $r=0.67, p<0.001 ; r=0.42, p<0.001 ; r=0.8, p<0.001$; $r=0.43, p<0.001 ; r=-0.49, p<0.001 ; r=0.3$, $p<0.001)$, respectively.

To investigate the correlation between the CTX-II concentration and the histopathological aging of articular cartilage, degeneration was detected as a significant correlation between CTX-II and age, with $p<0.05$. Furthermore, there was a highly significant correlation between COMP and DKK1 levels and grades of disease activity (DAS28) activity, with $p<0.001$ (Table 4). Linear regression for the three markers are presented in Table 5.

Table 3. Correlation between COMP, CTX-II, and DKK1 with clinical and laboratory data of the rheumatoid arthritis patients

\begin{tabular}{|c|c|c|c|c|c|c|}
\hline \multirow[t]{2}{*}{ Parameter } & \multicolumn{2}{|c|}{ COMP ng/ml } & \multicolumn{2}{|c|}{ CTX-II ng/ml } & \multicolumn{2}{|c|}{ DKK1 pg/ml } \\
\hline & $\boldsymbol{R}$ & $p$ & $\boldsymbol{R}$ & $p$ & $\boldsymbol{R}$ & $p$ \\
\hline Age, years & 0.03 & 0.838 & 0.28 & $0.026^{*}$ & 0.004 & 0.975 \\
\hline Disease duration, years & -0.13 & 0.324 & 0.002 & 0.988 & 0.09 & 0.458 \\
\hline Morning stiffness in hours & 0.04 & 0.819 & 0.07 & 0.714 & 0.37 & 0.053 \\
\hline Number of swollen joints & -0.28 & $0.026^{*}$ & -0.19 & 0.141 & 0.5 & $<0.001^{* * *}$ \\
\hline Number of tender joints & -0.33 & $0.007^{* *}$ & -0.16 & 0.218 & 0.67 & $<0.001^{* * *}$ \\
\hline Patient global score & -0.4 & $0.001^{* * *}$ & -0.18 & 0.166 & 0.42 & $0.001^{* *}$ \\
\hline DAS28 & -0.52 & $0.001^{* *}$ & -0.18 & 0.161 & 0.78 & $<0.001^{* *}$ \\
\hline WBCs & -0.13 & 0.304 & 0.17 & 0.192 & 0.11 & 0.393 \\
\hline HB level & 0.25 & $0.044^{*}$ & 0.14 & 0.264 & -0.49 & $<0.001^{* *}$ \\
\hline Platelet count & -0.23 & 0.069 & -0.09 & 0.452 & 0.3 & $0.017^{*}$ \\
\hline ESR & -0.39 & $0.002^{* *}$ & -0.04 & 0.749 & 0.43 & $0.001^{* *}$ \\
\hline $\mathrm{TNF}-\alpha \mathrm{pg} / \mathrm{ml}$ & -485 & $0.000^{* * *}$ & -0.190 & 0.136 & 0.242 & 0.057 \\
\hline IL-17 pg/ml & -0.425 & $0.001^{* *}$ & -0.168 & 0.187 & 0.213 & 0.094 \\
\hline
\end{tabular}

$\overline{D A S}$ - disease activity score, WBCs - white blood cells, HB - hemoglobin, ESR - erythrocytes sedimentation rate, TNF- $\alpha-$ tumor necrosis factor $\alpha$, IL-17 - interleukin 17; ${ }^{*}$ statistically significant correlation $(p<0.05),{ }^{* *}$ statistically significant correlation $(p<0.01)$

Table 4. Correlation between COMP, CTX-II, and DKK1 with grades of DAS28

\begin{tabular}{|c|c|c|c|c|c|}
\hline Parameter & Remission & Low & Moderate & High & $p$-value \\
\hline COMP ng/ml & $13.56 \pm 12.26$ & $13.67 \pm 13.26$ & $4.71 \pm 3.22$ & $2.4 \pm 2.41$ & $<0.001^{* *}$ \\
\hline CTX-II ng/ml & $0.52 \pm 0.22$ & $0.45 \pm 0.18$ & $0.49 \pm 0.29$ & $0.37 \pm 0.28$ & 0.093 \\
\hline DKK1 pg/ml & $3201.2 \pm 512.57$ & $3485.57 \pm 456.63$ & $5128.4 \pm 616.5$ & $7867.95 \pm 618.87$ & $<0.001^{* *}$ \\
\hline
\end{tabular}


Table 5. Linear regression for COMP, CTX-II, and DKK1

\begin{tabular}{lccccccccc}
\hline Parameter & \multicolumn{3}{c}{ COMP } & & & CTX-II & & \multicolumn{2}{c}{ DKK1 } \\
\hline Age, years & $\beta$ & $\boldsymbol{t}$ & Sig. & $\beta$ & $\boldsymbol{t}$ & Sig. & $\beta$ & $\boldsymbol{t}$ & Sig. \\
\hline Disease duration, years & 0.095 & 0.558 & 0.584 & 0.479 & 1.777 & 0.095 & 0.234 & 1.329 & 0.202 \\
\hline Morning stiffness in hours & 0.121 & 0.795 & 0.438 & -0.160 & -0.664 & 0.516 & 0.330 & 2.101 & 0.052 \\
\hline Number of swollen joints & 0.094 & 0.570 & 0.577 & 0.107 & 0.415 & 0.684 & -0.042 & -0.246 & 0.809 \\
\hline Number of tender joints & 0.458 & 2.040 & 0.058 & -0.298 & -0.840 & 0.413 & 1.126 & 4.860 & $0.000^{* *}$ \\
\hline Patient global score & 1.310 & 2.669 & $0.017^{*}$ & -0.965 & -1.247 & 0.230 & 1.314 & 2.596 & $0.019^{*}$ \\
\hline DAS28 & 0.155 & 0.571 & 0.576 & -0.527 & -1.229 & 0.237 & 0.588 & 2.098 & 0.052 \\
\hline ESR & -1.874 & -2.785 & $0.013^{*}$ & 1.454 & 1.370 & 0.190 & -2.052 & -2.958 & $0.009^{* *}$ \\
\hline WBCs & 0.294 & 0.987 & 0.339 & -0.584 & -1.245 & 0.231 & 0.901 & 2.938 & $0.010^{*}$ \\
\hline HB level & 0.040 & 0.226 & 0.824 & 0.258 & 0.927 & 0.368 & 0.077 & 0.425 & 0.677 \\
\hline Platelet count & 0.126 & 0.740 & 0.470 & 0.051 & 0.191 & 0.851 & -0.132 & -0.754 & 0.462 \\
\hline TNF- $\alpha$, pg/ml & -0.416 & -2.101 & $0.040^{*}$ & -0.341 & -1.555 & 0.125 & 0.205 & 0.932 & 0.355 \\
\hline IL-17, pg/ml & -0.084 & -0.422 & 0.675 & 0.112 & 0.509 & 0.613 & 0.045 & 0.203 & 0.840 \\
\hline DAS - disease activity score, WBCs - white blood cells, HB - hemoglobin, ESR - erythrocytes sedimentation rate, TNF- $\alpha-$ tumor necrosis factor $\alpha$,
\end{tabular}

\section{Discussion}

In spite of the fact that the determination of RA transfers on an accumulation of signs and manifestations bolstered by serology radiograph, there is a difficulty in building an early finding method for RA [31]. Besides, already established clinical example, RA has a tendency to rise after some time, and deficient example is frequently introduced in the early months or even years of the disease.

The prognostic significance of CTX-II debasement markers for ligament harm has been built up in various models of degenerative joint pain, for example, osteoarthritis (OA) [32-34]. Additionally, Mazieres et al. [35] recognized that patients with difficult hip OA in whom urinary CTX-II qualities were in the upper quartile of the dispersion had a more serious danger of movement than patients in the lower two quartiles of the circulation. Moreover, patients with excruciating hip OA in whom urinary CTXII qualities were in the upper quartile of the dispersal had a predominant danger of development than patients in the lower two quartiles of the dispersal. In our study, we found that CTX-II serum levels were altogether superior in RA patients contrasted with the solid gathering, which concurs that these ligament digestion variables might be tangled in the pathogenesis of RA. Furthermore, our study revealed that there was a strong correlation between serum levels of CTX-II and age, and thus it was related to the severity of articular cartilage degeneration and histopathological changes in the articular cartilage. This was in agreement with other studies who reported that CTX-II and RA were proposed as feasible biomarkers for early detection and monitoring of arthritic diseases, and their concentrations imitated the processes that was unswervingly implicated in the synthesis or degradation of articular cartilage and bone mineralization, which permitted a valuation over smaller periods of time compared to conservative radiography [23]. Good correlation of the levels of CTX-II to the sternness of knee cartilage blemishes on MRI in subjects with principally normal outcomes on radiographs has also been reported [13]. In humans, high concentrations of CTX-II levels in children to young adults (20 to 25 years) were defined, and steady levels were perceived in adults between 30 and 50 years [36]. However, high CTX-II levels and cartilage turnover were observed in young rats from 5 to 7 months of age [36].

The results of Mazieres et al. indicated an agreement with our review, there were a critical raises of C-receptive protein (CRP) before the start of clinical sickness [35]. In this manner, demonstrating the symptomatic estimation of serum CTX-II in the early motioning of joint aggravation is comparable to the benefit of measuring a systemic marker of irritation (CRP). Gradually, these discoveries will assign that CTX-II is an early pointer of joint aggravation as well as an impression of dynamic ligament harm. In our study, we found that serum CTX-II demonstrated affectability of $100 \%$ and specificity of $52.4 \%$, with cut-off $>0.15 \mathrm{ng} / \mathrm{ml}$, However, Jung et al. perceived that an uCTX-II exhibited a specificity of $87.5 \%$ and affectability of $75.5 \%$ for anticipating X-beam characterized knee OA [37].

A couple of years back, serum COMP test was propelled as the new marker for determination of RA. Our review uncovered that patients with RA had factually expanded serum COMP levels contrasted with the controls, and that the levels were contrarily associated with ESR, inflammatory cytokines (TNF- $\alpha$, IL-17), the quantity of swollen joints, delicate joints, quiet worldwide score, and the DAS28 score. Furthermore, serum COMP level of 3.6 
$\mathrm{ng} / \mathrm{ml}$ was the ideal cut-off, an incentive for perceiving between RA patients and sound subjects, where the rate of effectively grouped patients was $58.7 \%$ (i.e. affectability) and the rate accurately delegated not having RA was $85.7 \%$ (i.e. specificity). These discoveries were in concurrence with a study of El Defrawy et al., who revealed a fundamentally higher serum COMP in patients with RA contrasted to healthy subjects; nonetheless, serum levels were emphatically related to joint degradation [38].

Moreover, the negative relationship between serum COMP levels and both ESR and RF, presented predictable theory that aggravation and tissue demolition were not specifically connected in RA [39]. Additionally, Wisłowska's and Jabłońska's reviewed obviously maintained part for serum COMP as a marker, reflecting that the procedures were not specifically connected to the irritation in RA [40]. Thus, it was reported that expanded COMP levels in RA could be a potential marker of articular ligament harm [11] or it may reflect ligament turnover [41]. In view of this, we can state that serum COMP levels can possibly be utilized as an organic biomarker of inflammation and ligament digestion before radiographic discoveries in RA, which is by all accounts not connected with the fiery occasions. Nevertheless, it is still not clear whether the pattern level or the transient change in serum COMP levels is a superior indicator of joint devastation. The serum COMP levels in RA patients might be influenced by changing of medications during the course of disease, which may reflect ligaments harm. Along these lines, an estimations of this marker should be perceived that require additional clinical and longitudinal investigations of different varieties in COMP serum and its relationship with joint pain manifestations.

We additionally discovered expanded serum DKK1 levels in RA patients comparing to sound controls. Prominently, these abnormal states were decidedly connected with ESR, the quantity of swollen joints, delicate joints, quiet worldwide score, and the DAS28 score.

Our assessment agrees with the past review by Diarra et al. who evaluated DKK1 level both in serum and in the synovium of RA patients [42]. They concluded that DKK1 level was hoisted inside the synovium of RA patients than osteoarthritis patients, while serum DKK1 level was higher in RA patients than in healthy subjects. Furthermore, DKK1 level emphatically corresponded with infection movement [42] and the blockage of DKK1 terminated bone disintegration in an incendiary mouse model. In addition, Daoussis et al. revealed that serum levels of DKK1 were altogether expanded in patients with RA, which related with increased danger of bone disintegrations and osteoporosis [43]. Besides, a noteworthy reduction in the serum levels of DKK1 was seen with TNF-adversary treatment in those patients [42]. Moreover, in our study, we found that DKK1 level is a critical marker of disease progress, as it is altogether directly raised in high action RA patients as compared with patients with low action or those excluded. Thus, DKK1 may fill in as another clinical biomarker for RA patients.

\section{Conclusions}

Measurement of some serological biomarkers such as COMP, CTX-II, and DKK1 that reflect bone and ligament demolition in RA patients could be utilized to demonstrate early joint affection and disease progression, however, with low affectability and specificity. The COMP serum is a potential biomarker in RA, which indicates disease activity and damage to the articular cartilage as well as to monitor treatment efficacy.

\section{Acknowledgments}

With much gratitude, we would like to recognize the crucial role of the faculty of medicine of Assiut University, Assiut, Egypt, grant office unit for their fund (grant number: 015/12/2015), all required equipment, and necessary materials to complete our project. Last but not least, many thanks go to the head of the project, Prof. Mohamed El Sharkawy and Prof. Omar M Shaaban, whose have invested their full effort in guiding the team in achieving the goal. We would like to escalate the guidance given by other authors and the panels, particularly in our project presentation that has enhanced our performance skills thanks to their valued comments and advices.

The authors declare no conflict of interest.

\section{References}

1. Picerno V, Ferro F, Adinolfi A, et al. (2015): One year in review: the pathogenesis of rheumatoid arthritis. Clin Exp Rheumatol 33: 551-558.

2. Karsdal MA, Bay-Jensen AC, Leeming DJ, et al. (2013): Quantification of "end products" of tissue destruction in inflammation may reflect convergence of cytokine and signaling pathways - implications for modern clinical chemistry. Biomarkers 18: 375-378.

3. Mort JS, Billington CJ (2001): Articular cartilage and changes in arthritis: matrix degradation. Arthritis Res 3: 337-341.

4. Berdowska I (2004): Cysteine proteases as disease markers. Clin Chim Acta 342: 41-69.

5. Lauer-Fields JL, Juska D, Fields GB (2002): Matrix metalloproteinases and collagen catabolism. Biopolymers 66: 19-32.

6. Garnero P, Mazičres B, Guéguen A, et al. (2005): Cross-sectional association of 10 molecular markers of bone, cartilage, and synovium with disease activity and radiological joint damage in patients with hip osteoarthritis: the ECHODIAH cohort. J Rheumatol 32: 697-703.

7. Van Spil WE, DeGroot J, Lems WF, et al. (2010): Serum and urinary biochemical markers for knee and hip osteoarthritis: a systematic review applying the consensus BIPED criteria. Osteoarthritis Cartilage 18: 605-612. 
8. Bjornhart B, Juul A, Nielsen S, et al. (2009): Cartilage oligomeric matrix protein in patients with juvenile idiopathic arthritis: relation to growth and disease activity. $\mathrm{J}$ Rheumatol 36: $1749-1754$.

9. Agarwal P, Schulz JN, Blumbach K, et al. (2013): Enhanced deposition of cartilage oligomeric matrix protein is a common feature in fibrotic skin pathologies Matrix Biol 32: 325-331.

10. Saxne T, Heinegard D (1992): Cartilage oligomeric matrix protein: a novel marker of cartilage turnover detectable in synovial fluid and blood. Br J Rheumatol 31: 583-591.

11. Morozzi G, Fabbroni M, Bellisai F, et al. (2007): Cartilage oligomeric matrix protein level in rheumatic diseases: potential use as a marker for measuring articular cartilage damage and/or the therapeutic efficacy of treatments. Ann N Y Acad Sci 1108: 398-407.

12. Di Cesare PE, Carlson CS, Stollerman ES, et al. (1997): Expression of cartilage oligomeric matrix protein by human synovium. FEBS Lett 412: 249-252.

13. Mouritzen U, Christgau Lehmann HJ, Tankó LB, Christiansen C (2003): Cartilage turnover assessed with a newly developed assay measuring collagen type II degradation products: influence of age, sex, menopause, hormone replacement therapy, and body mass index. Ann Rheum Dis 62: 332-336.

14. Neidhart M, Hauser N, Paulsson M, et al. (1997): Small fragments of cartilage oligomeric matrix protein in synovial fluid and serum as markers for cartilage degradation. Br J Rheumatol 36: 1151-1160.

15. Andersson ML, Svensson B, Petersson IF, et al. (2013): Early increase in serum-COMP is associated with joint damage progression over the first five years in patients with rheumatoid arthritis. BMC Musculoskelet Disord 14: 229.

16. Das BR, Roy A, Khan FR (2015): Cartilage oligomeric matrix protein in monitoring and prognostication of osteoarthritis and its utility in drug development. Perspect Clin Res 6: 4-9.

17. De Jong Z, Munneke M, Vilim V, et al. (2008): Value of serum cartilage oligomeric matrix protein as a prognostic marker of large-joint damage in rheumatoid arthritis - data from the RAPIT study. Rheumatol 47: 868-871.

18. Nikolaisen C, Rekvig OP, Nossent HC (2007): Diagnostic impact of contemporary biomarker assays for rheumatoid arthritis. Scand J Rheumatol 36: 97-100.

19. Bender AL, da Silveira IG, von Mühlen CA, Staub HL (2010): High specificity but low sensitivity of the cartilage oligomeric matrix protein (COMP) test in rheumatoid arthritis and osteoarthritis. Clin Chem Lab Med 48: 569-570.

20. Wislowska M, Jablońska B (2005): Serum cartilage oligomeric matrix protein (COMP) in rheumatoid arthritis and knee osteoarthritis. Clin Rheumatol 24: 278-284.

21. Pinzone JJ, Hall BM, Thudi NK, et al. (2009): The role of Dickkopf-1 in bone development, homeostasis, and disease. Blood 113: 517-525.

22. Krishnan V, Bryant HU, Macdougald OA (2006): Regulation of bone mass by Wnt signaling. J Clin Invest 116: 1202-1209.

23. Duclos ME, Roualdes O, Carraro R, et al. (2010): Significance of the serum CTX-II level in an osteoarthritis animal model: a 5-month longitudinal study. Osteoarthritis Cartilage 18: 1467-1476.

24. Goldring SR, Goldring MB (2007): Eating bone or adding it: The wnt pathway decides. Nat Med 13: 133-134.

25. Cici D, Corrado A, Rotondo C, Cantatore FP (2019): Wnt Signaling and Biological Therapy in Rheumatoid Arthritis and Spondyloarthritis. Int J Mol Sci 22: 5552.

26. Korb A, Tohidast-Akrad M, Cetin E, et al. (2006): Differential tissue expression and activation of p38 mapk alpha, beta, gamma, and delta isoforms in rheumatoid arthritis. Arthritis Rheum 54: 2745-2756.

27. Daoussis D, Liossis SN, Solomou EE, et al. (2010): Evidence that dkk-1 is dysfunctional in ankylosing spondylitis. Arthritis Rheum 62: 150-158.

28. Aletaha D, Neogi T, Silman AJ, et al. (2010): Rheumatoid arthritis classification criteria an American College of Rheumatology/European League Against Rheumatism. Arthritis Rheum 62: 2569-2581.

29. Prevoo ML, van't Hof MA, Kuper HH, et al. (1995): Modified disease activity scores that include twenty-eight-joint counts. Development and validation in a prospective longitudinal study of patients with rheumatoid arthritis. Arthritis Rheum 38: 44-48.

30. Hanly J, McNeil B (1982): The meaning and the use of the area under a receiver operating characteristics (ROC) curve. Radiology 143: 29-36.

31. Catrina AI, Joshua V, Klareskog L, Malmström V (2016): Mechanisms involved in triggering rheumatoid arthritis. Immunol Rev 269: 162-174.

32. Sharif M, Kirwan J, Charni N, et al. (2007): A 5-yr longitudinal study of type IIA collagen synthesis and total type II collagen degradation in patients with knee osteoarthritis-association with disease progression. Rheumatology 46 : 938-943.

33. Reijman M, Hazes JM, Bierma-Zeinstra SM, et al. (2004): A new marker for osteoarthritis: cross-sectional and longitudinal approach. Arthritis Rheum 50: 2471-2478.

34. Kimura M, Matsukawa A, Ohkawara, et al. (1997): Blocking of TNF-alpha and IL-1 inhibits leukocyte infiltration at early, but not at late grade of S. aureus-induced arthritis and the concomitant cartilage destruction in rabbits. Clin Immunol Immunopathol 82: 18-25.

35. Mazičres B, Garnero P, Guéguen A, et al. (2006): Molecular markers of cartilage breakdown and synovitis at baseline as predictors of structural progression of hip osteoarthritis. The ECHODIAH Cohort. Ann Rheum Dis 65: 354-359.

36. Tomiya M, Fujikawa K, Ichimura S, et al. (2009): Skeletal unloading induces a full-thickness patellar cartilage defect with increase of urinary collagen II CTx degradation marker in growing rats. Bone 44: 295-305.

37. Jung M, Christgau S, Lukoschek M, et al. (2004): Increased urinary concentration of collagen Type II C-telopeptide fragments in patients with osteoarthritis. Pathobiology 71: 70-76.

38. El Defrawy AO, Gheita TA, Raslan HM, et al. (2016): Serum and synovial cartilage oligomeric matrix protein levels in early and established rheumatoid arthritis. Z Rheumatol 75: 917-923.

39. Lipsky PE, van der Heijde DM, St Clair EW, et al. (2000): Infliximab and methotrexate in the treatment of rheumatoid arthritis. Anti-Tumor Necrosis Factor Trial in Rheumatoid Arthritis with Concomitant Therapy Study Group. N Engl J Med 343: 1594-1602.

40. Wisłowska M, Jabłońska B (2005): Serum cartilage oligomeric matrix protein (COMP) in rheumatoid arthritis and knee osteoarthritis. Clin Rheumatol 24: 278-283.

41. Posey KL, Hecht JT (2008): The role of cartilage oligomeric matrix protein (COMP) in skeletal disease. Curr Drug Targets 9: 869-877.

42. Diarra D, Stolina M, Polzer K, et al. (2007): Dickkopf-1 is a master regulator of joint remodeling. Nat Med 13: 156-163.

43. Daoussis D, Liossis SN, Solomou EE, et al. (2010): Evidence that Dkk-1 is dysfunctional in ankylosing spondylitis. Arthritis Rheum 62: 150-158. 